\title{
Community-based grassroot communication strategies, process and product: The drawings that saved our hospital
}

\author{
Michel Mounayar*, RA; Professor of Architecture ${ }^{1}$ \\ ${ }^{1}$ Ball State University, Muncie Indiana. USA
}

\begin{abstract}
A case-study analysis of an urban design communication strategy employed by our university-based design team entrusted with re-envisioning the uncertain future of a local small-town community hospital in Indiana. The design process is carefully constructed from structured public input, and community participation, whereby students, faculty, physicians, nurses, as well as ordinary citizens combine their efforts to strategically develop their 'plan for planning'. Finding a strategy to define the scope of their future needs and the definition of important priorities to organize the project scope prior to engaging professional consultants. In this scenario, the design team is only the guide and translator, working closely with stakeholders to help them visualize and clarify the aspirations of their town. This paper will present our community-based design methods and most importantly our graphic communication techniques, specifically formulated to envision and facilitate consensus for a new unified public health system in a small Midwestern American city.
\end{abstract}

\section{Community-based design}

Over the last five decades, our university program used grassroot methodologies to demystify the design process and democratize the town planning decision-making. To that end, we developed and refined methods to engage the public through specific graphical techniques especially designed for public participation and input. In the following, we will explore one such case-study for Dekalb Health System in Dekalb county Indiana, looking specifically to present our method and outcomes.

As urban designers, how do we converse with the lay public? What graphic tools must we use to help our communities invent and envision a prosperous and designed future? Employing community-based design processes are we able to assist an endangered small county hospital in northern Indiana plan for its public health strategy? What graphic tools do we deploy to change public preconception, while also resolving ongoing community conflicts? These communication questions are the principal focus for this analysis.

\footnotetext{
*Corresponding author: Professor Michel Mounayar, RA mmounaya@bsu.edu
} 
The process succeeded, and this small county overcame the challenges confronting it. To this date, the hospital continues to provide high quality, locally-sourced, healthcare for its citizen. In this age of mega corporate mergers, where bigger is better, we propose to illustrate a unique story where the large corporate takeover threat ceded control to health managed at the local level through a modest 50-bed not-for-profit county-owned and managed hospital.

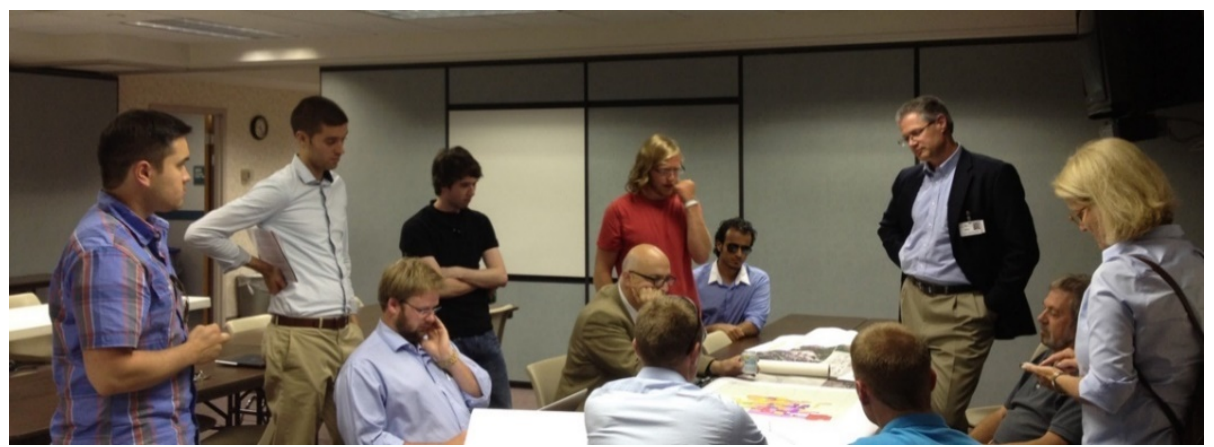

Fig. 1. Team discussion, Dekalb Charrette team, students, faculty, and hospital physicians and administrators working to map community input.

Such a small hospital is predictably under continual hostile attacks from larger, profitdriven, health systems in the region. Health is big business in our country. The United States is the last industrialized country with no national healthcare system that guarantees health coverage to all its citizens. Moderate to low income individuals and most families struggle to meet unexpected rising costs of healthcare, and medicine. "On a per capita basis, health spending has increased over 30-fold in the last four decades, from $\$ 355$ per person in 1970 to $\$ 10,739$ in 2017 . In constant 2017 Dollars, the increase was almost 6 -fold (600\% percent) from $\$ 1,797$ in 1970 to $\$ 10,739$ in 2017 " based on data from the Kaiser Family Foundation Analysis (12/2018). The challenge seems to grow exponentially every year, resulting in double digit price increases. What might be perceived as a right in some countries, is surprisingly considered as a privilege in ours.

As our national healthcare debate matures, designers must actively participate in the conversation. The health care problem is fundamentally a "design project" requiring creativity and the integration of disparate and competing interests into synthesized practical and workable solutions. The challenge is complex and requires tools and techniques that will clarify needs and constraints, artfully weaving both into a comprehensive complex working system. Design graphics and communication strategy are central for both success and innovation. Our techniques include onsite photography, digital modeling, and digital and analog sketching. However, the public nature of our visioning process is perhaps the secret for our success. Bringing the planning process into the open requires engaging the different stakeholders in public prompting all involved to use a common language for these discussions. Preferably, one that is equally new and fresh to all participants, so as preconceptions and restrictive and convoluted history does not get in the way of progress. Design language and graphics provide such a common channel for all participants to communicate with one another. Napoleon Bonaparte said "a good sketch is better than a long speech", expressing the power of graphics to bridge differences and create vision for action. So, our sketches and plans form the foundation for a new open conversation based on candidness and clarity, helping us overcome the public's bias and leading the group to invest in imagination. Our process is rooted in our belief that success hinges on open data driven 
decision making. Consequently, graphically interpreting and visualizing data is the secret to our success.

\section{The Charrette Process}

At the invitation of the community, our university-based student/faculty design team, joined efforts with local health professionals, physicians, politicians, business managers, and citizens to safeguard a fragile but successful hospital, preventing its demise due to the threat of a looming corporate takeover, helping it and the community avoid entering their county into health desert status.

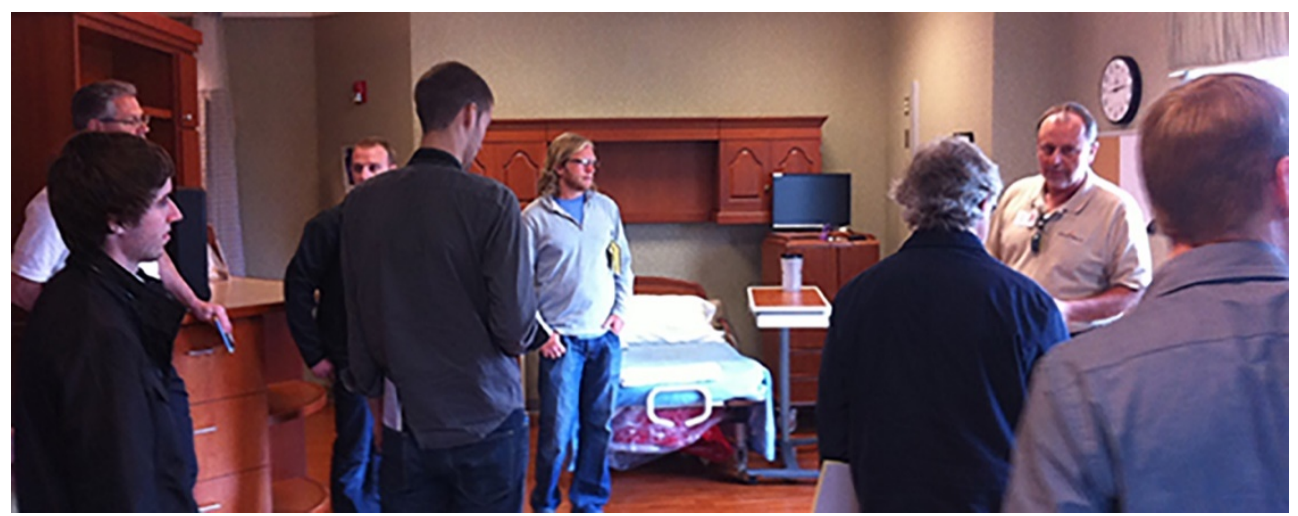

Fig. 2. Design team touring the facilities with hospital staff.

This case-study also examines our public participatory process, graphics, and techniques used to safeguard the hospital. Our design concept builds on the importance of adopting total community wellness through design, where the hospital joins local partners to provide a synergistic comprehensive health and wellness program for the entire county. Community organizations such as the YMCA, City Hall, organic food growers, school districts, as well as cultural and artistic not-for-profit organizations join forces to develop what we termed "Complete Community Wellness" (CCW). Architecture students' involvement in the project was invaluable and benefited both the community and the academy. Students offer a level of neutrality facilitating stakeholders' collaboration allowing them to find common ground, so they may set aside their political rivalries, encouraging them to collaborate. In return, the students receive a unique and special educational experience not available in the confines of a studio or classroom. Realtime progress and community feedback show our young designers their social responsibility and their immeasurable impact on the community. Our university is committed to immersive learning, where students and faculty are imbedded in towns and cities working on real problems affecting real people. 


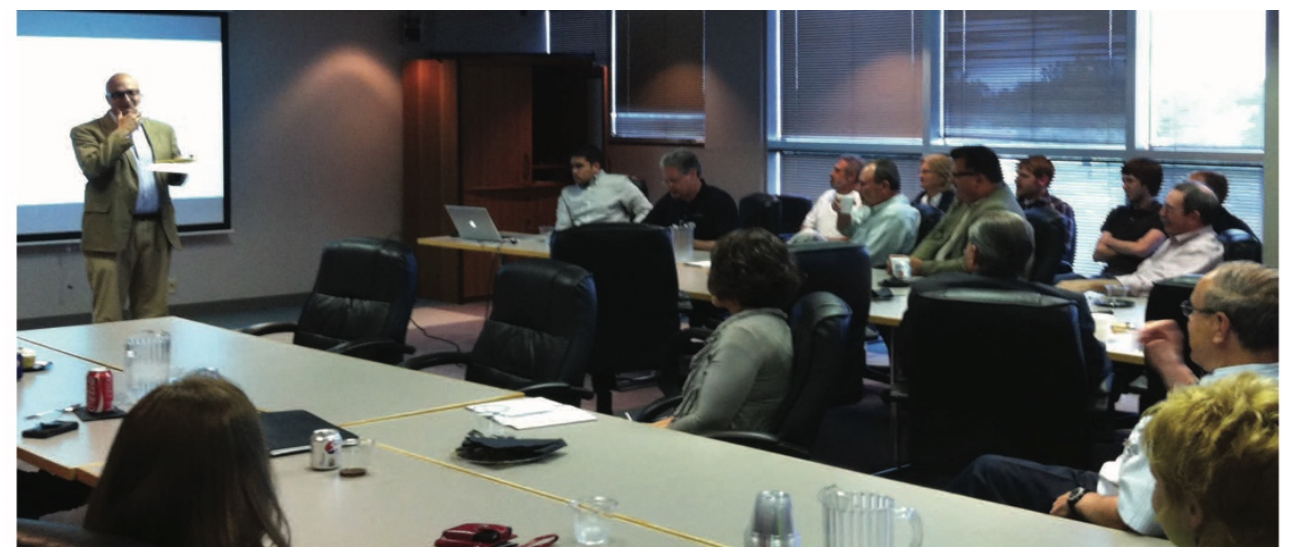

Fig. 3. Public presentation of analysis data and findings.
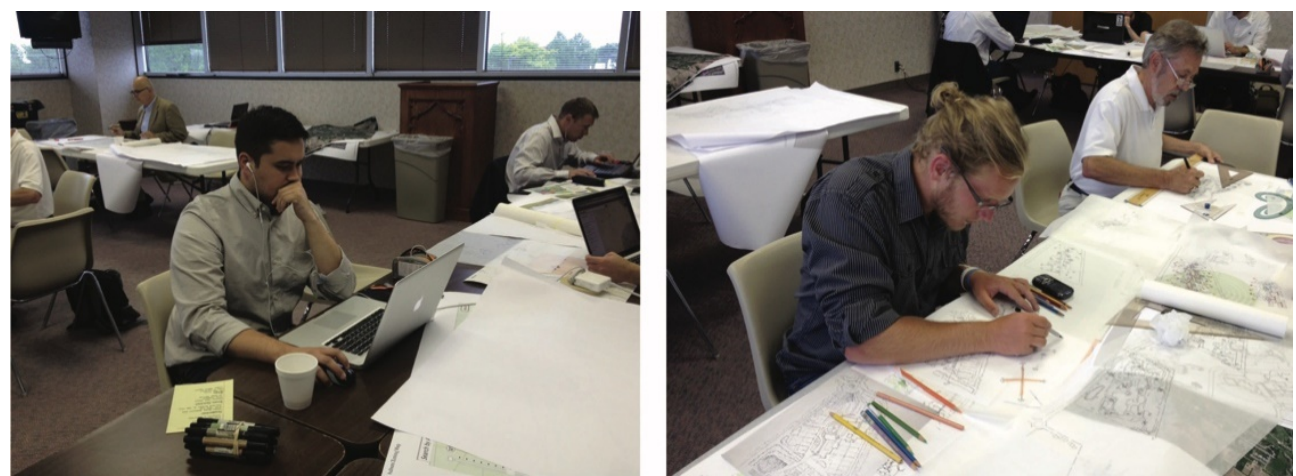

Fig. 4. The studio is public open to all participants. The drawings develop under the preview of the community.

\subsection{The Storefront Studio}

The studio must be open and accessible to all citizens. Often improvised by the host town using donated vacant storefront retail spaces, city hall meeting rooms, church basements, library multipurpose rooms, or any available and open real estate in town. However, the studio must be visible and central to the community. Participants must feel invited and free to visit at their convenience. Keeping the studio public helps the team gain credibility. The studio must facilitate involving the community in both the definition and resolution of the design challenge.

\subsection{The Charrette Team}

For the duration of the charrette, the team lives with volunteer host families. Taking residence in the community demonstrates the team's commitment towards its citizens. The interaction and stories exchanged in residence are an essential part of the process.

Pedagogically, removing students from the confines of the academy and allowing them to enter our communities is greatly impactful to their professional growth. The students find purpose in engaging real design problems. Charrettes often start with strategic meetings engaging special focus groups seldom in contact with the academy. In the meetings, students conduct interviews with diverse stakeholders and community leaders. Providing the students 
direct contact with mayors, council members, city crews, transportation specialist, police chiefs, educators, professionals, and technicians. These focus groups assist the team with clear formulation of the project's problem definition. For the students, learning in the field is memorable and dynamic. Student feedback shows that they garner high level of value from their workshop participation. Such concentrated field experiences are typically inspirational and life changing for them. The essence of the experience is the blurring of boundaries between learners and teachers. The obscuring of these boundaries allows for open and clear communication. Students forget their obsession with grades and focus on outcomes. In this context, feedback is blunt, clear, and immediate. Success is measured by the level of public understanding of the designers' proposals. Grades are circumstantial and meaningless. Effectiveness and success are ubiquitously on display, all the time, as the project unfolds. This format makes learning a byproduct of doing. However, success is guaranteed by the simple act of participation. The value rests in experiencing all the community forces, in real time, as they struggle to shape their decision-making, while actively searching for, and finding their illusive community leaders. On display for the students is also the role of the architects as agents of positive change. The facilitators and problem solvers who synthesize complex demands and incongruent information into meaningful and wholistic design solutions.

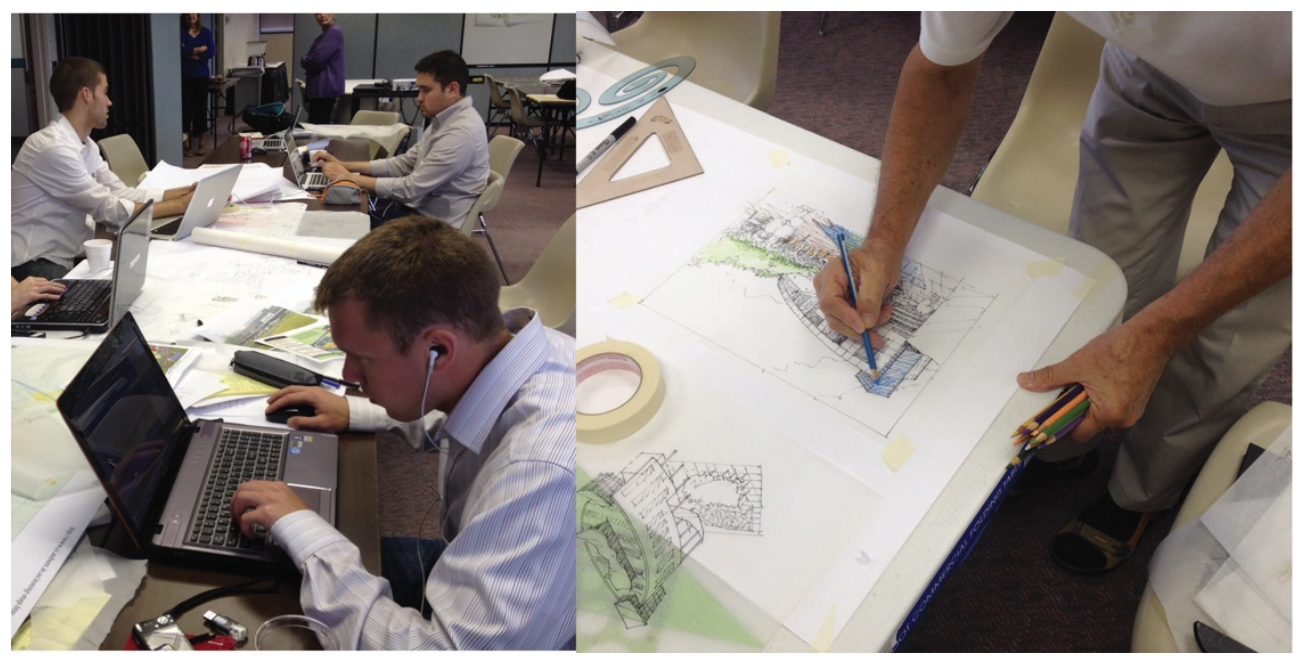

Fig. 5. The team relies on both analogue and digital graphics.

\subsection{The communication strategies}

The public and the open nature of the process is what is critical here. The fact that the drawings are forming in real time and in public for all to see, gives them deeper meaning for the community. Consequently, the magic is not really about the superiority or any uniqueness of our drawings, as much as where we draw them! Taking the design process to the public is the secret!

Employing a myriad of graphic tools, developed during our university's long history (50+ years) of community-based projects, we can change the conversation for all concerned citizens and town elders in support of their community hospital. The strategy consisted of five phases. First, the development of an expanded steering committee (Growing leadership). Second, undertake a factfinding search through interviews with focus groups. Third, the design team prepares a clear presentation showing a visitor's perspective of the context. 
Forth, an open public presentation of finding, showing several potential strategies for future development. Fifth, a final project steering committee meeting dedicated to analyzing the charrette drawings and developing a detailed prioritized project list, as well as, an implementation schedule. As the process matures, the community concludes that the hospital is more than a place to visit when one is sick. Through the years, the facility and programs became an integral civic part of the town. Stakeholders graphicly discover illustrated strategies that could assist the group secure state and federal funding.

\section{The drawings}

Public conversations must be free of technical jargon. Two-dimensional graphics such as plans, sections, and elevations are too abstract for most community members. Our team mostly relies on three-dimensional graphics such as eye-level perspectives and axonometric drawings. We find that atmospheric drawings are more accessible to residents. Drawings must also remain in progress, unfinished, as to keep them focused on ideas and not become finished pieces of detailed architecture. If the drawings are too realistic the team risks the conversation shifting from general concepts to specific opinion or objections about style and taste. Ambiguity in this case is powerful! It allows the viewers' imagination to inhabit and complete the images in their mind. Furthermore, the designers should always present multiple options of the plan. Developing a singular direction for the design increases the potential for binary positive or negative acceptance. While having multiple proposals facilitates the conversation about potential alternate designs and concepts. Keeping the dialogue alive.
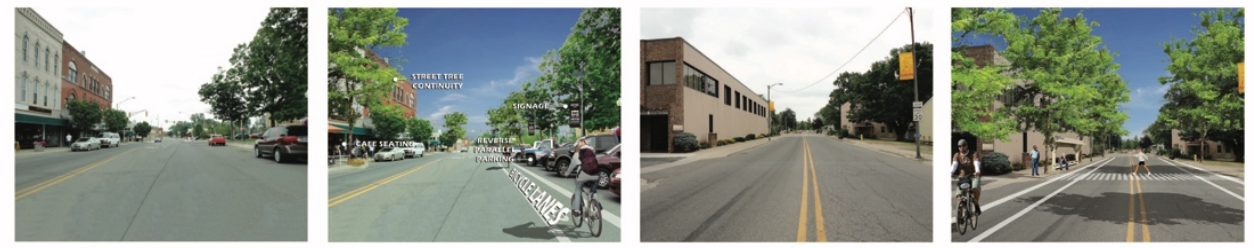

Fig. 6. Emphasizing the need to improve community walkability. The team uses digital sketching to illustrate the potential specific street improvement to achieve this goal.
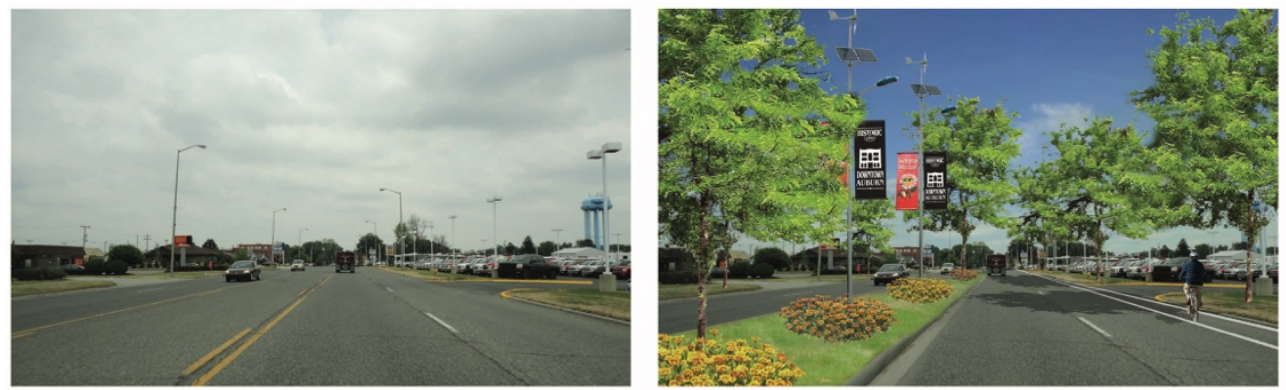

Fig. 7. Community entries may be improved with strategic interventions. Digital sketches showing proposed median, bikeways, and landscape. 


\section{A vision of Complete Community Wellness (CCW)}

The wellbeing of a community is beyond just the quality of hospitals and doctors. Health and wellness rely on a complex system with multiple moving parts, pressure points, and components. Our analysis identified both assets and liabilities for the project area. On the adverse side significant air and water pollution challenges were mapped and recorded graphically. Also, access to medical professionals and the ability to afford care were equally identified as major challenges for residents. Conversely, the intimate scale of the hospital, and the personal familiarity of the community with the medical staff are complemented among the most important assets to the group. Doctors, nurses, and hospital administrators are neighbors and friends. Patients feel a precious connection to the hospital staff. Perhaps, this is the most significant factor that motivate the community to fend off the takeover of their facility and safeguard this institution. Dekalb Health truly existed as a community hospital since the early 1920 s.

Our vision imagines the hospital transforming into a community hub focused on the concept of "Complete Community Wellness". The hospital through this concept provides the community with meeting space, art galleries, a YMCA like exercise gym, pools, and programs in additions to the best medical facilities in the area. The grounds will promote health through walking trails and open gardens that might even provide community gardening and other public and civic amenities. In this manner, the community hospital connects closely with its public. Schools, parks, playgrounds, and gyms are part of the system that will keep us active and healthy. After several days of focus group meetings with community stakeholders, the hospital staff identified the following important health indicators the community must monitor and manage:

- Obesity rates

- Chronic illness associated with being overweight such as diabetes, High blood pressure, and cardiac disease

- Residents' Physical activity levels

- Healthy eating options

- $\quad$ Smoking rates

- Community aesthetics

- Educational and employment achievement

These important markers exceed strictly medical data, suggesting the importance of context and location. Where you live and what you eat are as much a factor to one's wellbeing as biology and genetics. The physical environmental design must take into consideration the level of satisfaction, fulfillment, and activity of the inhabitants. We need to achieve health and wellness through the implementation of designed environments that prevent destructive ailments such as obesity, stress, and depression. The intent here is rooted in the idea that the county must establish an ongoing partnership with the hospital for one's life-long wellness. A preventive system that cares equally for both healthy, as well as, ill individuals. Complete Community Wellness (CCW) is a holistic and system wide concern for: young and old, physical and emotional wellbeing, short and long-term health. $\mathrm{CCW}$ is more inclusive in its consideration of healthy living. Exercise, fun, and socializing are as important as food, medicine, technology, and science. The goal is to design an arrangement of infrastructure, programs, facilities, support technical staff, physicians, nurses that make up a total system that promote health through wellness. Consequently, access to gyms, sidewalks, bikeways, open fields, sports facilities, parks, healthy and safe food supply, clean water, places to meet 
and socialize are equally important to the availability of top-notch physicians, surgical suites, MRI units, or any other contemporary high-tech medical technology.

The concept is built on a total and complete approach to body, mind, and spirit, tended to and managed by the community hospital. All aspects of human life, spiritual, mental, and physical is orchestrated in partnership between the hospital, the county, educational, and social organizations, food growers, and the business community. Keeping our citizen healthy is dependent on how active and lively our cities and towns become. DeKalb Community Hospital is already engaged with its partners to seek such an innovative and exciting future.

\section{Three design concepts}

The team develops three different concepts specifically designed for the community's and the hospital's consideration. All three concepts recommend the transformation of the hospital into a community cultural and activities center, where medicine, arts, culture, exercise, and social gatherings are open to all residents. Beyond the center, the hospital also is recommended to establish smaller neighborhood-based outreach clinics that might be located although the county in both urban and rural settings. The future hospital master plan is imagined using three different approaches:

\subsection{Filling-in the gap}

Just like most hospitals, Dekalb health grew organically through the years without the guidance of a clear master plan. A maze of corridors and hallways confuse patients and visitors alike. Floor plate heights and existing mechanical installations limit the ability to update the required medical systems. Consequently, the intervention uses direct connection between important nodes, in the spirit of "a straight line is the shortest distance between two points." The principal goal for this approach is to work just outside the existing infrastructure on the perimeter of the existing buildings to provide strategic infill pieces designed specially to improve overall patient orientation, enhance staff circulation, while also expand the site with new quiet exterior gardens, as well as, new community-wide active public trails. The proposal adds new sections just outside the existing building façades providing for new nurses' stations, clearly connected corridors, and state of the arts patient rooms. Intervening to the front of the existing building also allows the hospital to showcase the organization's new progressive, and environmentally responsive image. Additionally, the new structure may be constructed without substantial day-to-day operational disruption. As requested by the project steering committee, new informal meeting rooms are located at the extreme tips of the new structure taking advantage of views and sunlight. These rooms are designed to serve as multipurpose rooms for the main patient floors. 


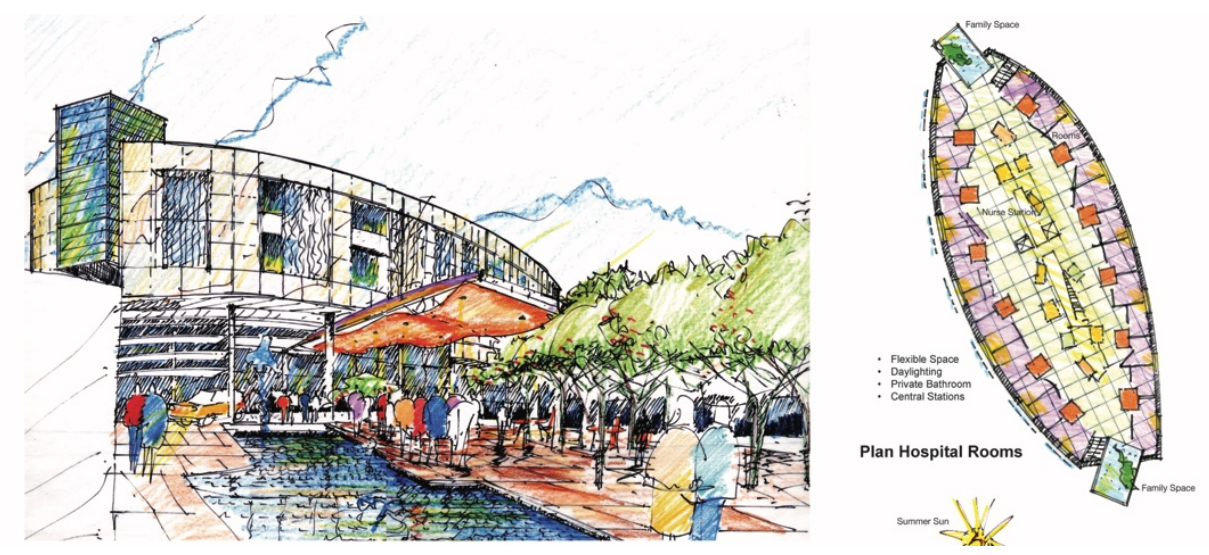

Fig. 8. Sketch showing how "filling in the gap" may provide the hospital a new image while updating and modernizing the existing infrastructure.

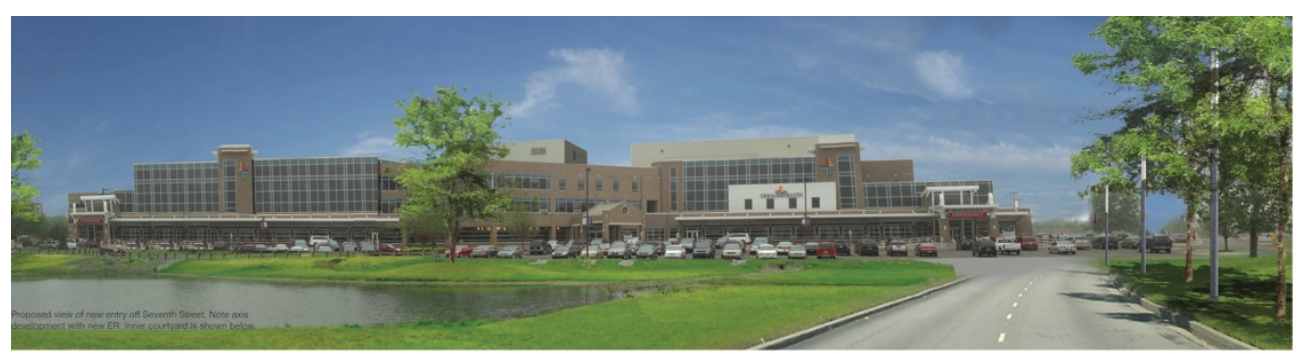

Fig. 9. Digital sketch showing the proposed courtyard campus.

\subsection{Courtyard wellness}

This concept emphasizes the importance of exterior natural spaces for the speedy recovery of patients. New construction provides a series of connected courtyards. Each designed to fulfill different wellness activities. The courtyards have the potential to bring young and old together for special activities including gardening and food production. These spaces also become an integral part of wayfinding landmarks for patients and visitors. If each takes on a unique character, then visitors may use them as orientation markers. Although, such open space arrangement surrounded by programmed buildings, may increase daily walking distances for occupants, but the advantages of daylighting and the availability of natural views outweigh this inconvenience. The addition of a new YMCA sports facility, outpatient doctor offices, plus new eateries and art galleries provide the themes for the new courtyard masterplan. 


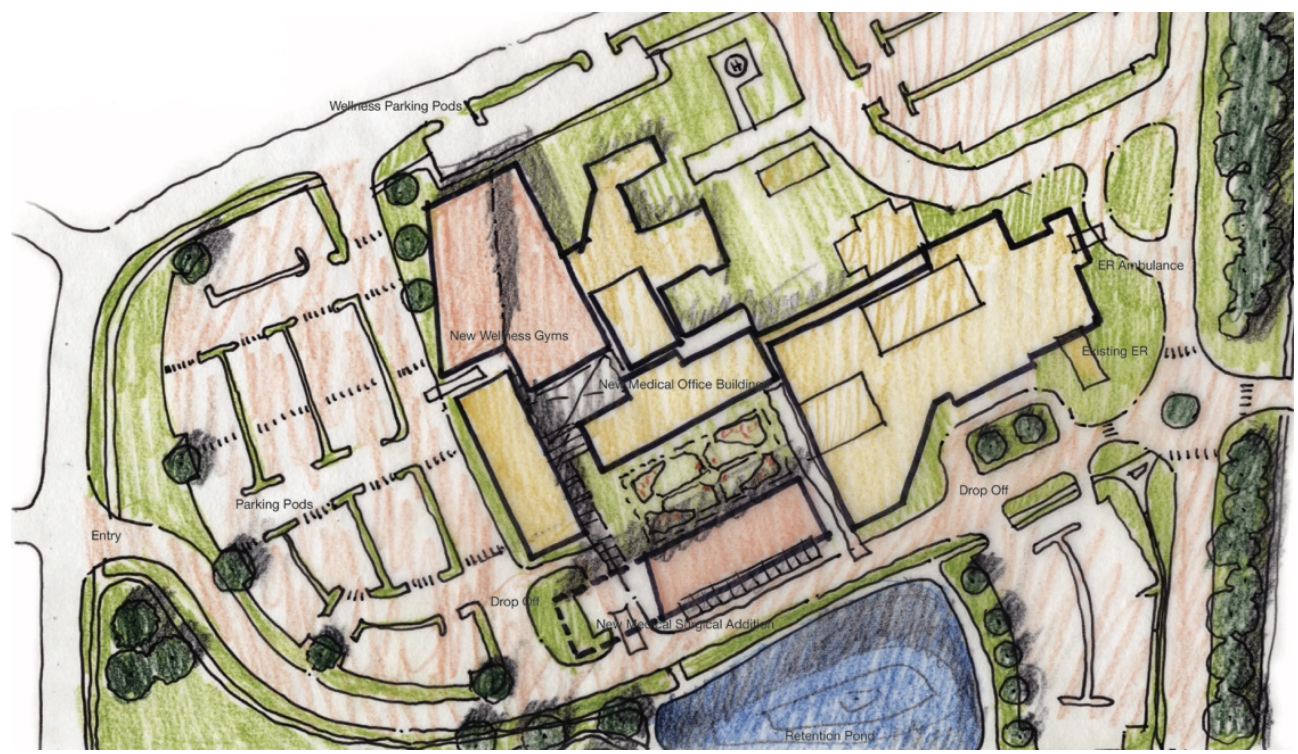

Fig. 10. Proposed courtyard masterplan development.

\subsection{New campus}

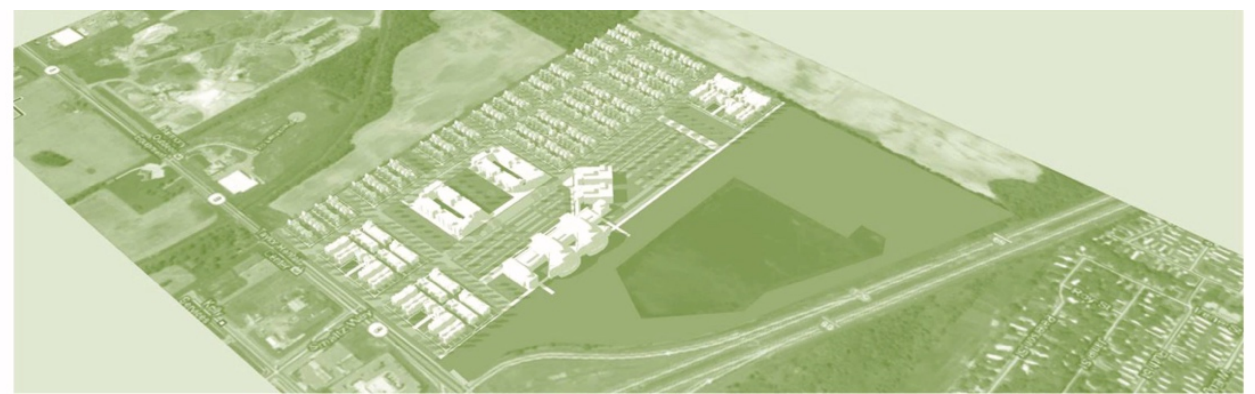

Fig. 11. Team's illustration of potential all new wellness/hospital campus near the interstate highway.

Influential members of the steering committee were intrigued by the possibility of moving the entire hospital out of the downtown and developing a clean-slate totally new campus in the hinterlands of the county, on farmland, near the main interstate highway. They believed that the old structure limits the hospital options and would increase the ultimate cost for the project. Most corporate hospitals are building new operations around Dekalb county and this newly establish campus, in their mind, has a better chance to fend off the takeover attempts and would safeguard the hospital. 


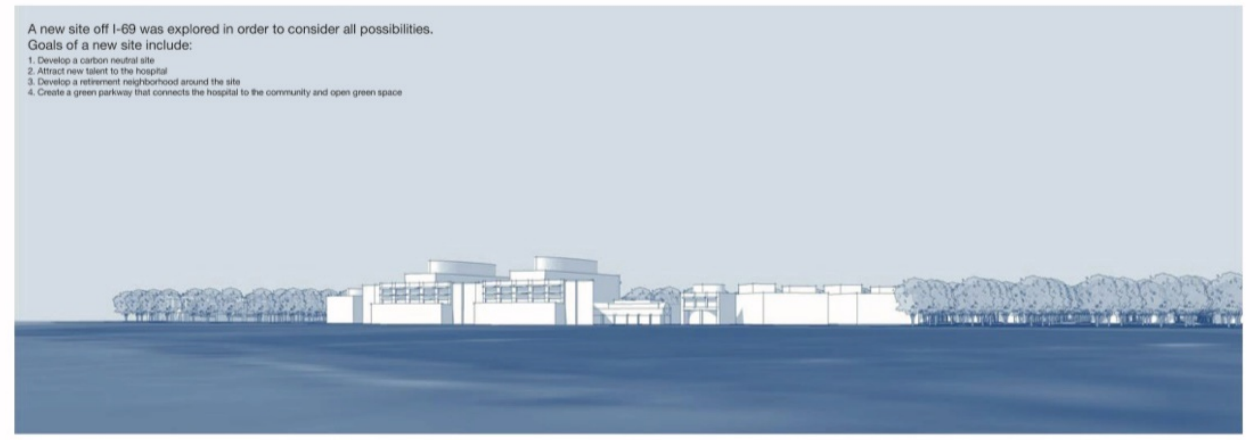

Fig. 12. View from the interstate showing the new hospital neighborhood.

Although our design team disagreed with this assessment, it was important for us to seriously explore this alternative. To ignore it, and disregard this faction's interest, would have cost us our neutrality as project facilitators, and would have potentially led to the overall failure of our team. So, we assigned one of our most senior medical facilities expert colleague for the development of this design option. The group put together an extensive site selection process, as well as a fully conceived regional hospital/office/housing neighborhood master plan. This development option may be now readily evaluated more effectively compared with the two other options presented. The issue was no longer abstract, nor emotional for all concerned. Having these drawings is very important for the project steering committee.

\section{Conclusion}

Architects and designers are important to the healthcare debate in the United States. Health should be considered as an integral part of town design. Once patients enter the complex and costly system of hospitals, physicians, and medication the opportunity to prevent and protect is missed. Our physical environment must promote healthy living. We must provide our citizens active, engaging, inspiring, and esthetically pleasing neighborhoods, towns and cities. Walking and physical activity must be designed as part of daily life. Even if one never visits the gym, the act of living in a certain location should results in an active lifestyle. Activity, clean air, and food are all improved through design. The designers' ability to illustrate and organize information gives them the capacity to help with such complex problems. But unfortunately, often, they are not consulted. The Dekalb Health case-study showcases how the work of a university community-based projects design team of students and faculty, using participatory illustrations, successfully conceived a new and exciting healthcare future for a small Indiana town.

\section{References}

1. H Leyland, Ø Naess, The effect of area of residence over the life course on subsequent mortality, J R Stat Soc Ser A Stat Soc. 2009 Jun ; 172(3) : 555-578

2. R Kamal, C Cox, Kaiser Family foundation, How has U.S. spending on healthcare changed over time? (2016) https://www.healthsystemtracker.org/chart-collection 